\title{
Microscopic Evaluation of the Effect of Oral Microbiota on the Development of Bisphosphonate-Related Osteonecrosis of the Jaws in Rats
}

\author{
Felipe M. Silveira ${ }^{1}$, Adriana Etges ${ }^{1}$, Marcos B. Correa ${ }^{1}$, Ana Carolina U. Vasconcelos ${ }^{1}$ \\ ${ }^{1}$ Dental College, Federal University of Pelotas - UFPel, Rio Grande do Sul, Porto Alegre, Brazil.
}

\section{Corresponding Author:}

Ana Carolina Uchoa Vasconcelos

Serviço de Patologia Bucal, Universidade Federal de Pelotas - UFPel

CEP: 96015-560, Rua Gonçalves Chaves, 457, Sala 607, Pelotas-RS

Brasil

Phone: +55 5332256741

Fax: +55 5332256741

E-mail: carolinauv@gmail.com

\begin{abstract}
Objectives: Osteonecrosis of the jaws is a side effect associated with the use of bisphosphonates. Using histologic analysis, this study aimed to evaluate the influence of microbial colonies in the development of osteonecrosis in the jaws of rats subjected to nitrogenous and non-nitrogenous bisphosphonates, undergoing surgical procedures.

Material and Methods: Thirty-four rats (Rattus norvegicus, Wistar strain) were allocated randomly into three groups: 12 animals treated with zoledronic acid; 12 animals treated with clodronate; and 10 animals treated with saline. Sixty days after the start of treatment, the animals underwent three extractions of the upper right molars. After 120 days of drug administration, the rats were killed. Histologic analysis was performed on specimens stained with hematoxylin and eosin by the technique of manual counting points using Image-Pro Plus software on images of the right hemimaxilla.

Results: Osteonecrosis was induced in the test groups. There was no statistically significant association between the presence of microbial colonies and the presence of non-vital bone (Kruskal-Wallis, $\mathrm{P}>0.05$ ).

Conclusions: Use of zoledronic acid was associated with non-vital bone and the results suggested that the presence of microbial colonies does not lead to osteonecrosis.
\end{abstract}

Keywords: bisphosphonate-associated osteonecrosis of the jaw; diphosphonates; infection.

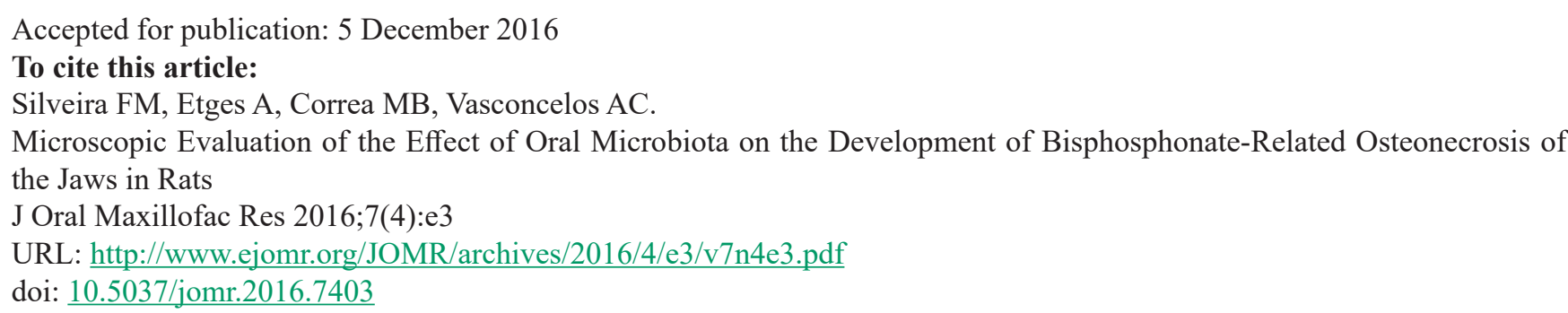




\section{INTRODUCTION}

Bisphosphonates (BPs) are potent inhibitors of osteoclast function and are widely used as the treatment of choice or adjuvant therapy for osteoporosis, Paget disease, bone metastasis and hypercalcemia of malignancies $[1,2]$. These drugs are chemically classified into two main groups: nonnitrogenated and nitrogenated. The nitrogenated drugs are much more potent []] .

Bisphosphonate-related osteonecrosis of the jaws (BRONJ), first recognized by Marx in 2003 [4], is an important side effect of BP therapy. Clinically, BRONJ is characterized as an area of exposed bone in the jaws persisting for more than 8 weeks in a patient currently or previously exposed to these drugs and with no history of head and neck radiation therapy [4-6]. The major risk factors for BRONJ are tooth extractions, poor oral hygiene, conditions of immunosuppression, route of administration (intravenous or oral BPs), type of BP (non-nitrogenated or nitrogenated), and treatment duration $[\underline{7}, \underline{8}]$.

The pathogenesis of BRONJ has not been fully elucidated and it is believed that it has a multifactorial origin [5]. The causal factors are basically related to four mechanisms: (1) inhibition of bone remodelling, where osteoclasts are the main cellular target of $\mathrm{BFs}$, affecting bone remodeling; (2) inhibition of angiogenesis, where the vascular supply is interfered; (3) toxic effects of BPs on the oral epithelium, where the normal healing of the soft tissue is affected and (4) infection, where the presence of a complex biofilm on exposed bone is an important component for the development of the disease $[\underline{5}, \underline{8}, \underline{9}]$.

The management of BRONJ is based on stage and size of the lesions, requiring different degrees of surgical or non-surgical interventions strategies [10]. Treatment options may range from improving of the oral hygiene conditions and administration of systemic antibiotic therapy to, in more severe cases, surgery with debridement of the affected area [11]. In addition, other therapeutic methods for BRONJ are being investigated, including low-level laser therapy, hyperbaric oxygen therapy and platelet-derived growth factor locally applied [12-14].

Few studies have shown the effects of microorganisms on the development of BRONJ. The relationship between the causal factors and the development of the injury requires further investigation for better understanding. Using histologic analysis, this study aims to evaluate the influence of microbial colonies on the development of bisphosphonate-related osteonecrosis of the jaws in the jaws of rats subjected to therapy with nitrogenous and non-nitrogenous bisphosphonates.

\section{MATERIAL AND METHODS Animals}

This study was approved by the Ethics Committee, School of Dentistry, Pontifical Catholic University of Rio Grande do Sul, Brazil (protocol no. 09/00083). The procedures were carried out in accordance with institutional guidelines for animal care and use. The sample comprised 34 female rats (Rattus norvegicus, Wistar strain) from the animal facility of Federal University of Pelotas; the mean age was 120 days and the mean weight was $230 \mathrm{~g}$ (standard deviation 0.5). The animals were individually identified on their tail and housed in plastic cages (5 per cage) placed in ventilated racks (Alesco, Monte Mor, SP, Brazil) at a temperature of $22{ }^{\circ} \mathrm{C}$ with a $12 \mathrm{~h}$ light/dark cycle (lights on at 7:00 AM and off at 7:00 PM). During the experiments, a standard diet of rat chow (Nuvilab, Colombo, PR, and Brazil) and filtered water were provided ad libitum. The animals were randomly selected according to the different colours marked in their tails and allocated into three groups, based on the BP used (intraperitoneal administration every 28 days):

- Zoledronic acid group: 12 animals treated with the nitrogen-containing BP zoledronic acid $(0.6 \mathrm{mg} /$ $\mathrm{kg}$ ) (Novartis Pharma AG, Basel, Switzerland);

- Clodronate group: 12 animals treated with the non-nitrogen-containing BP clodronate $(20 \mathrm{mg} /$ $\mathrm{kg}$ ) (Jenahexal Pharma $\mathrm{GmbH}$, Thuringia, Germany);

- Control group: 10 animals that were given saline solution $(0.9 \%$ sodium chloride).

\section{Surgical procedures}

All animals were subjected to tooth extraction on the right side of the maxillae. Oroscopy was done after anaesthetized to certify that there were no previous oral lesions. Tooth extractions were performed 60 days after the beginning of the experiment. The animals were anesthetized with a single intraperitoneal injection of a mixture of ketamine hydrochloride 5\% (100 mg/kg; Vetbrands, Jacareí, SP, Brazil) and xylazine hydrochloride $2 \%(10 \mathrm{mg} / \mathrm{kg}$; Vetbrands). The three upper molars were extracted using an adapted 3s spatula (SSWhite, Duflex, Rio de Janeiro, RJ, Brazil) for luxation and paediatric forceps (Edlo, Canoas, RS, Brazil) with the functional portion adapted to the size of the tooth. 


\section{Euthanasia of the animals and dissection of the maxillae}

After completing 120 days of drug administration, the animals were euthanized by deep anaesthesia with isoflurane (Cristalia, Porto Alegre, RS, Brazil) in an appropriate anaesthesia chamber. The maxillae were then surgically removed and fixed for $24 \mathrm{~h}$ in $10 \%$ buffered formalin (TopGlass, Porto Alegre, RS, Brazil).

\section{Histological processing and analysis}

The specimens were cut into two fragments in the coronal direction, using a steel sanding disc at low speed and subjected to decalcification in ethylenediaminetetraacetic acid (EDTA; Biodinâmica, Ibiporã, PR, Brazil) solution for 30 days. They were then embedded in paraffin, cut into $4 \mu \mathrm{m}$ sections, and stained with hematoxylin and eosin.

The histological sections were digitized using an Olympus BX51 light microscope (Media Cybernetics, Silver Spring, MD, USA), connected to an Olympus DP72 video camera (Media Cybernetics, Silver Spring, MD, USA) and an Image-Pro Capture Kit Platform (Media Cybernetics, Silver Spring, MD, USA). The images were captured using a x20 objective and stored in tagged image file (.tiff) format. The images were analysed using the manual counting technique in the Image-Pro Plus 4.5.1 software (Media Cybernetics, Bethesda, MD, USA). The program allows the digital image to be captured overlain with a grid to allow areas of interest to be marked and counted.

Sixty-eight histologic slides stained with hematoxylin and eosin stain were documented. Initially, the slides were prepared from the right side where the molars were extracted. Subsequently, the entire length of the hemimaxilla on the same side was examined. To do this, the images were obtained to accommodate an area $540 \mu \mathrm{m}$ in height and $540 \mu \mathrm{m}$ in length, covering the entire area. The guide for the movement of discards was obtained by MeasureTool 5 software (X-Rite, Inc. Grand Rapids, Michigan, USA). Quantitative analysis was performed for the following variables: non-vital bone, microbial colonies, and root fragments. The microbial colony count was based on the morphological characteristics compatible to Actinomyces sp.: structures organized in a sunbeam pattern bound together by an eosinophilic material adhering to the surface [15].

A 713-point grid was superimposed on each image, and each point was counted according to the matching morphological structures (Figure 1). Data were stored in Microsoft Excel, version 2013 (Microsoft Corporation, Redmond, WA, USA).

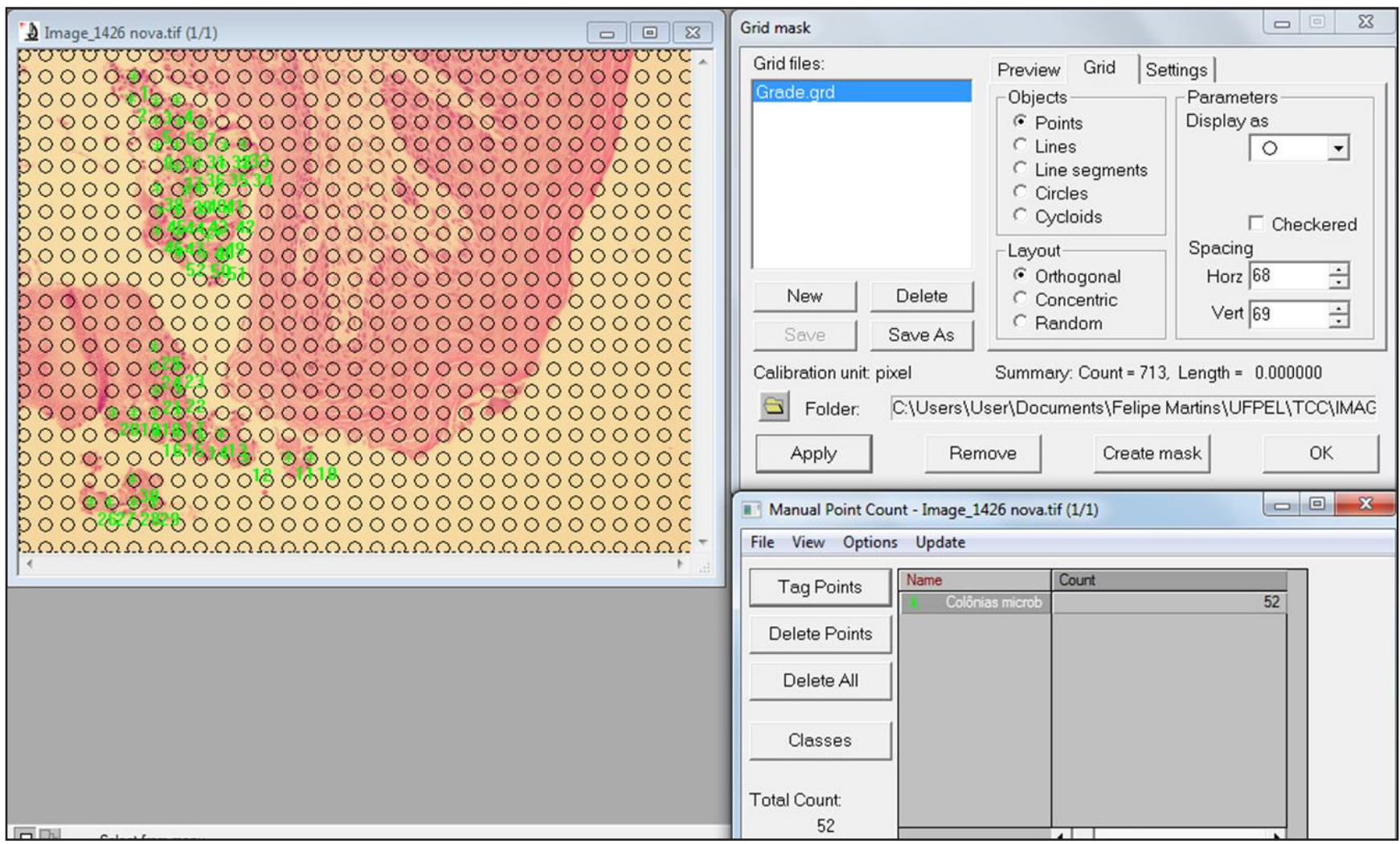

Figure 1. Quantification of microbial colonies in one of the fields evaluated using Image Pro Plus 4.5.1 software (Media Cybernetics, Bethesda, MD, USA) (hematoxylin and eosin stain, original magnification x20). 


\section{Statistical analysis}

The images were analysed by an examiner who had been calibrated and was blinded to the conditions. Calibration consisted of evaluating a series of 20 histologic images, twice, at two different time points. The results of these two evaluations were subjected to a paired t test and Pearson's correlation coefficient, to show the absence of a significant difference $(\mathrm{P}>0.05)$ and a strong correlation $(r>0.9)$.

The data were analysed by descriptive statistics, the Fisher exact test and the Kruskal-Wallis test complemented by the multiple comparisons test; the level of significance was set at 5\%. The statistics were processed using SPSS 17.0 software (Statistical Package for the Social Sciences, IBM, Chicago, IL, USA).

Parametric data were expressed as mean and standard deviation (M [SD]).

\section{RESULTS}

\section{Non-vital bone}

On oral examination before tooth extractions, no animals exhibited oral mucosal lesions. Table 1 shows the results for the frequency (presence/absence) of non-vital bone on each group. Non-vital bone was present in all groups. Using the Fisher exact test, it was observed that zoledronic acid was associated with non-vital bone $(\mathrm{P}<0.001)$.

Table 1. Sample distribution according to the presence/absence of non-vital bone

\begin{tabular}{l|c|c|c|c}
\hline \multirow{2}{*}{\multicolumn{1}{c|}{ Group }} & \multicolumn{3}{c}{ Non-vital bone } \\
\cline { 2 - 5 } & \multicolumn{2}{|c|}{ Present } & \multicolumn{2}{c}{ Absent } \\
\cline { 2 - 5 } & $\mathbf{N}$ & $\mathbf{\%}$ & $\mathbf{N}$ & $\mathbf{\%}$ \\
\hline Zoledronic acid & $11^{\mathrm{a}}$ & $91.6^{\mathrm{a}}$ & 1 & 8.3 \\
\hline Clodronate & 5 & 41.6 & 7 & 58.3 \\
\hline Control & 2 & 20 & 8 & 80 \\
\hline
\end{tabular}

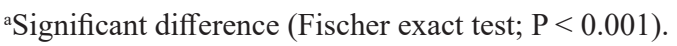
$\mathrm{N}=$ number of animals

\section{Microbial colonies}

Table 2 shows the results for the frequency (presence/ absence) of microbial colonies. Using the Fisher exact test, it was observed that all groups showed an association with microbial colonies $(\mathrm{P}<0.001)$.

\section{Microbial colonies and root fragments}

The results for the histological evaluation of microbial colonies and root fragments are presented in Table 3. There was no significant difference between the variables and non-vital bone (Kruskal-Wallis, $\mathrm{P}>0.05)$.

\section{DISCUSSION}

The use of rats in studies involving assessment of the oral biofilm is justified by the presence of similarities between the oral microbiota of this animal model and humans [16]. However, animal studies relating to pharmaceuticals and environmental agents may be a not valid predictor of human experience. These types of studies should always respect the rules of Reduction, Replacement and Refinement suggested by Russell and Burch [17] in 1959. Therefore, the number of animals should be the minimum required to achieve a valid statistically significant result and the use of alternative methods, based on computer simulation or in vitro testing, are preferred.

Table 2. Sample distribution according to presence/absence of microbial colonies

\begin{tabular}{l|c|c|c|c}
\hline \multirow{2}{*}{\multicolumn{1}{c|}{ Group }} & \multicolumn{3}{c}{ Microbial colonies } \\
\cline { 2 - 5 } & \multicolumn{2}{|c}{ Present } & \multicolumn{2}{c}{ Absent } \\
\cline { 2 - 5 } & $\mathbf{N}$ & $\mathbf{\%}$ & $\mathbf{N}$ & $\mathbf{\%}$ \\
\hline Zoledronic acid & $9^{\mathrm{a}}$ & $75^{\mathrm{a}}$ & 3 & 25 \\
\hline Clodronate & $11^{\mathrm{a}}$ & $91.6^{\mathrm{a}}$ & 1 & 8.3 \\
\hline Control & $7^{\mathrm{a}}$ & $70^{\mathrm{a}}$ & 3 & 30 \\
\hline
\end{tabular}

a Significant difference (Fischer exact test; $\mathrm{P}<0.001$ ). $\mathrm{N}=$ number of animals.

Table 3. Quantification of the histologic features (hematoxylin and eosin stain) in the zoledronic acid, clodronate and control groups

\begin{tabular}{l|c|c|c|c|c|c|c|c|c}
\hline \multirow{2}{*}{$\begin{array}{c}\text { Histological } \\
\text { features }\end{array}$} & \multicolumn{4}{|c|}{ Zoledronic acid } & \multicolumn{3}{c}{ Clodronate } & \multicolumn{3}{c}{ Control } \\
\cline { 2 - 11 } & Mean & SD & Median & Mean & SD & Median & Mean & SD & Median \\
\hline Microbial colonies & 39.8 & 48.7 & 26.8 & 42.7 & 39.6 & 34.3 & 25.7 & 57.2 & 5.25 \\
\hline Root fragments & 120.4 & 142.9 & 92.8 & 88.5 & 61 & 110.5 & 51.3 & 68.7 & 20.5 \\
\hline
\end{tabular}

Kruskall-Wallis $(\mathrm{P}>0.05)$.

$\mathrm{SD}=$ standard deviation 
In addition, investigations must be always refined in order to decrease potential suffering of the involved animals.

The present research examined the effects of microorganisms on the development of osteonecrosis associated with the use of a nitrogenated BP (zoledronic acid) and a non-nitrogen BP (clodronate) in rats. It was necessary to assess whether the condition was present before performing the surgical procedures. Non-vital bone was observed in all groups. However, only the zoledronic acid group showed a statistically significant association with this variable. This result is in agreement with other in vivo studies reporting increased frequency of BRONJ in users of nitrogenated BPs, particularly zoledronic acid [18-21]. It is possible to infer that the extraction procedure is a risk factor for the development of BRONJ, which is in agreement with the results of other laboratorial and clinical studies $[4,22,23]$.

Actinomyces sp. have been identified in microscopic and scanning electron microscope studies of BRONJ [10]. All groups in this study showed microbial colonies compatible with Actinomyces sp. This result is consistent with other research that demonstrates in vivo, using histopathologic analysis, the presence of microorganisms in bone specimens from patients with BRONJ $[21,24-27]$. It is believed that bacterial clusters in the oral cavity have the ability to cause pathologic bone loss through three mechanisms: (1) destruction of noncellular components of the bone by releasing acids and proteases; (2) induction of cellular processes that stimulate bone degradation; and (3) inhibition of the synthesis of bone matrix $[\underline{8}, \underline{28}, \underline{29}]$.

Although Actinomyces sp. and non-vital bone were present in all groups, there was no statistically significant association between the two variables in the groups assessed. It is known that BRONJ is associated with a multi-species mixed population [15]. Aftimos et al. [30] evaluated the microbiological characteristics of patients diagnosed with BRONJ using histopathology analysis, and observed the presence of fungal infection in all cases. Sedghizadeh et al. [29] verified the type of biofilm present in patients with BRONJ by electron microscopy and histologic analysis. In their study, Fusobacterium, Bacillus, Actinomyces, Candida, Staphylococcus, Streptococcus, Selenomonas, and Treponemas species were observed. The authors concluded that the presence of fungal and bacterial colonies associated with the absence of osteoclasts in resorption areas could contribute to the development of the disease.
Furthermore, Ji et al. [31] mapped the profile of patients with BRONJ, with and without treatment with antibiotics, using a polymerase chain reaction with the bone fragments adjacent to soft tissue injury. The authors noted that while the groups showed different types of bacterial colonization, Actinomyces sp. was present in both groups.

This study evaluated the presence of microbial colonies morphologically consistent with Actinomyces $\mathrm{sp}$. in groups treated with different BPs. It is possible, as discussed earlier, that other microorganisms are directly involved in the development of BRONJ, and Actinomyces sp. have an adjunctive role. This is consistent with the findings observed in this study. In the present research, the microorganisms were stained exclusively with hematoxylin and eosin stain, which limits the investigation.

Oral microbial colonies do not cause any pathology if the integrity of the mucosal barrier is not affected. For colonization to occur, a combination of patient susceptibility and the presence of potentially pathogenic microorganisms are necessary $[\underline{15}, \underline{32}]$. It is known that patients using nitrogenous and non-nitrogenous BPs intravenously usually have some degree of immunosuppression. In the present study, the groups were not subjected to any form of immunosuppression. It is possible that this has affected the results obtained in this study. Still, the lack of a significant association between root fragments and non-vital bone suggests that the conditions observed arise from the type of BP used, because the results exclude the participation of this variable in the development of the disease.

The influence of infectious agents on BRONJ pathogenesis has not yet been completely clarified. Thus, studies that aim to quantify and classify the types of microorganisms involved in the development process of the disease are necessary. Besides, the strong correlation between BRONJ and nitrogenated BPs reported in clinical studies raise doubts about the possibility of different types of interaction of microorganisms in cases of BRONJ induced by nitrogenated and non-nitrogenated BPs.

\section{CONCLUSIONS}

The results of this study showed that zoledronic acid was associated with non-vital bone and that there was no statistically significant association between the presence of microbial colonies and the presence of non-vital bone. Despite the limitations of the present work, it is suggested that the presence of microbial colonies is not involved with osteonecrosis. 


\section{ACKNOWLEDGMENTS AND DISCLOSURE STATEMENTS}

The authors report no conflicts of interest related to this study.
We thank to Dr. Ana Paula Nunes (Federal University of Pelotas, Medicine College) for permitting the use of laboratory facilities.

We are also grateful to language editor Lorna O'Brien for editing English language.

\section{REFERENCES}

1. Ruggiero SL. Bisphosphonate-related osteonecrosis of the jaw: an overview. Ann N Y Acad Sci. 2011 Feb;1218:38-46. [Medline: 20946580] [doi: 10.1111/j.1749-6632.2010.05768.x]

2. Senel FC, Kadioglu Duman M, Muci E, Cankaya M, Pampu AA, Ersoz S, Gunhan O. Jaw bone changes in rats after treatment with zoledronate and pamidronate. Oral Surg Oral Med Oral Pathol Oral Radiol Endod. 2010 Mar;109(3): 385-91. [Medline: 20060339] [doi: 10.1016/j.tripleo.2009.10.011]

3. Russell RG. Bisphosphonates: mode of action and pharmacology. Pediatrics. 2007 Mar;119 Suppl 2:S150-62. [Medline: 17332236] [doi: 10.1542/peds.2006-2023H]

4. Marx RE. Pamidronate (Aredia) and zoledronate (Zometa) induced avascular necrosis of the jaws: a growing epidemic. J Oral Maxillofac Surg. 2003 Sep;61(9):1115-7. [Medline: 12966493] [doi: 10.1016/S0278-2391(03)00720-1]

5. Ruggiero SL, Dodson TB, Fantasia J, Goodday R, Aghaloo T, Mehrotra B, O’Ryan F; American Association of Oral and Maxillofacial Surgeons. American Association of Oral and Maxillofacial Surgeons position paper on medicationrelated osteonecrosis of the jaw--2014 update. J Oral Maxillofac Surg. 2014 Oct;72(10):1938-56. [Medline: 25234529] [doi: 10.1016/j.joms.2014.04.031]

6. Sigua-Rodriguez EA, da Costa Ribeiro R, de Brito AC, Alvarez-Pinzon N, de Albergaria-Barbosa JR. Bisphosphonaterelated osteonecrosis of the jaw: a review of the literature. Int J Dent. 2014;2014:192320. [Medline: 24868206] [PMC free article: 4020455] [doi: 10.1155/2014/192320]

7. Saussez S, Javadian R, Hupin C, Magremanne M, Chantrain G, Loeb I, Decaestecker C. Bisphosphonate-related osteonecrosis of the jaw and its associated risk factors: a Belgian case series. Laryngoscope. 2009 Feb;119(2):323-9. [Medline: 19172621] [doi: 10.1002/lary.20076]

8. Boff RC, Salum FG, Figueiredo MA, Cherubini K. Important aspects regarding the role of microorganisms in bisphosphonate-related osteonecrosis of the jaws. Arch Oral Biol. 2014 Aug;59(8):790-9. [Medline: 24859766] [doi: 10.1016/j.archoralbio.2014.05.002]

9. Allen MR, Burr DB. The pathogenesis of bisphosphonate-related osteonecrosis of the jaw: so many hypotheses, so few data. J Oral Maxillofac Surg. 2009 May;67(5 Suppl):61-70. [Medline: 19371816] [doi: 10.1016/j.joms.2009.01.007]

10. Ruggiero SL. Diagnosis and Staging of Medication-Related Osteonecrosis of the Jaw. Oral Maxillofac Surg Clin North Am. 2015 Nov;27(4):479-87. [Medline: 26293329] [doi: 10.1016/j.coms.2015.06.008]

11. Khan A, Morrison A, Cheung A, Hashem W, Compston J. Osteonecrosis of the jaw (ONJ): diagnosis and management in 2015. Osteoporos Int. 2016 Mar;27(3):853-9. [Medline: 26493811] [doi: 10.1007/s00198-015-3335-3]

12. Martins MA, Martins MD, Lascala CA, Curi MM, Migliorati CA, Tenis CA, Marques MM. Association of laser phototherapy with PRP improves healing of bisphosphonate-related osteonecrosis of the jaws in cancer patients: a preliminary study. Oral Oncol. 2012 Jan;48(1):79-84. [Medline: 21940198] [doi: 10.1016/j.oraloncology.2011.08.010]

13. Mozzati M, Gallesio G, Arata V, Pol R, Scoletta M. Platelet-rich therapies in the treatment of intravenous bisphosphonaterelated osteonecrosis of the jaw: a report of 32 cases. Oral Oncol. 2012 May;48(5):469-74. [Medline: 22265335] [doi: 10.1016/j.oraloncology.2011.12.004]

14. Freiberger JJ, Padilla-Burgos R, McGraw T, Suliman HB, Kraft KH, Stolp BW, Moon RE, Piantadosi CA. What is the role of hyperbaric oxygen in the management of bisphosphonate-related osteonecrosis of the jaw: a randomized controlled trial of hyperbaric oxygen as an adjunct to surgery and antibiotics. J Oral Maxillofac Surg. 2012 Jul;70(7):1573-83. [Medline: 22698292] [doi: 10.1016/j.joms.2012.04.001]

15. Anavi-Lev K, Anavi Y, Chaushu G, Alon DM, Gal G, Kaplan I. Bisphosphonate related osteonecrosis of the jaws: clinico-pathological investigation and histomorphometric analysis. Oral Surg Oral Med Oral Pathol Oral Radiol. 2013 May;115(5):660-6. [Medline: 23601221] [doi: 10.1016/j.00oo.2013.03.001]

16. Hyde ER, Luk B, Cron S, Kusic L, McCue T, Bauch T, Kaplan H, Tribble G, Petrosino JF, Bryan NS. Characterization of the rat oral microbiome and the effects of dietary nitrate. Free Radic Biol Med. 2014 Dec;77:249-57. [Medline: 25305639] [doi: 10.1016/j.freeradbiomed.2014.09.017]

17. Russell WMS, Burch RL. The principles of humane experimental technique. Wheathampstead: Universities Federation for Animal Welfare; 1959. [URL: http://altweb.jhsph.edu/]

18. Diel IJ, Fogelman I, Al-Nawas B, Hoffmeister B, Migliorati C, Gligorov J, Vääänen K, Pylkkänen L, Pecherstorfer M, Aapro MS. Pathophysiology, risk factors and management of bisphosphonate-associated osteonecrosis of the jaw: Is there a diverse relationship of amino- and non-aminobisphosphonates? Crit Rev Oncol Hematol. 2007 Dec;64(3):198-207. [Medline: 17855108] [doi: 10.1016/j.critrevonc.2007.07.005] 
19. Maahs MP, Azambuja AA, Campos MM, Salum FG, Cherubini K. Association between bisphosphonates and jaw osteonecrosis: a study in Wistar rats. Head Neck. 2011 Feb;33(2):199-207. [Medline: 20848442] [doi: 10.1002/hed.21422]

20. Quesnel AM, Seton M, Merchant SN, Halpin C, McKenna MJ. Third-generation bisphosphonates for treatment of sensorineural hearing loss in otosclerosis. Otol Neurotol. 2012 Oct;33(8):1308-14. [Medline: 22935809] [PMC free article: 3442123] [doi: 10.1097/MAO.0b013e318268d1b3]

21. Miranda-Rius J, Brunet-Llobet L, Lahor-Soler E, Giménez-Rubio JA. Concomitant factors leading to an atypical osteonecrosis of the jaw in a patient with multiple myeloma. Case Rep Med. 2014;2014:281313. [Medline: 25140178] [PMC free article: 4124701] [doi: 10.1155/2014/281313]

22. Marx RE, Sawatari Y, Fortin M, Broumand V. Bisphosphonate-induced exposed bone (osteonecrosis/osteopetrosis) of the jaws: risk factors, recognition, prevention, and treatment. J Oral Maxillofac Surg. 2005 Nov;63(11):1567-75. [Medline: 16243172] [doi: 10.1016/j.joms.2005.07.010]

23. Ruggiero SL, Fantasia J, Carlson E. Bisphosphonate-related osteonecrosis of the jaw: background and guidelines for diagnosis, staging and management. Oral Surg Oral Med Oral Pathol Oral Radiol Endod. 2006 Oct;102(4):433-41. [Medline: 16997108] [doi: 10.1016/j.tripleo.2006.06.004]

24. Merigo E, Manfredi M, Meleti M, Corradi D, Vescovi P. Jaw bone necrosis without previous dental extractions associated with the use of bisphosphonates (pamidronate and zoledronate): a four-case report. J Oral Pathol Med. 2005 Nov;34(10):613-7. [Medline: 16202082] [doi: 10.1111/j.1600-0714.2005.00351.x]

25. Bisdas S, Chambron Pinho N, Smolarz A, Sader R, Vogl TJ, Mack MG. Biphosphonate-induced osteonecrosis of the jaws: CT and MRI spectrum of findings in 32 patients. Clin Radiol. 2008 Jan;63(1):71-7. [Medline: 18068792] [doi: 10.1016/j.crad.2007.04.023]

26. Hansen T, Kunkel M, Springer E, Walter C, Weber A, Siegel E, Kirkpatrick CJ. Actinomycosis of the jaws--histopathological study of 45 patients shows significant involvement in bisphosphonate-associated osteonecrosis and infected osteoradionecrosis. Virchows Arch. 2007 Dec;451(6):1009-17. [Medline: 17952459] [doi: 10.1007/s00428-007-0516-2]

27. Lobato JV, Maurício AC, Rodrigues JM, Cavaleiro MV, Cortez PP, Xavier L, Botelho C, Hussain NS, Santos JD. Jaw avascular osteonecrosis after treatment of multiple myeloma with zoledronate. J Plast Reconstr Aesthet Surg. 2008;61(1):99-106. [Medline: 18068658] [doi: 10.1016/j.bjps.2006.06.016]

28. Nair SP, Meghji S, Wilson M, Reddi K, White P, Henderson B. Bacterially induced bone destruction: mechanisms and misconceptions. Infect Immun. 1996 Jul;64(7):2371-80. [Medline: 8698454] [PMC free article: 174085]

29. Sedghizadeh PP, Kumar SK, Gorur A, Schaudinn C, Shuler CF, Costerton JW. Identification of microbial biofilms in osteonecrosis of the jaws secondary to bisphosphonate therapy. J Oral Maxillofac Surg. 2008 Apr;66(4):767-75. [Medline: 18355603] [doi: 10.1016/j.joms.2007.11.035]

30. Aftimos V, Zeinoun T, Bou Tayeh R, Aftimos G. Bisphosphonate related osteonecrosis of the jaw: a study of 18 cases associated with fungal infection. Int J Dent. 2014;2014:869067. [Medline: 24696686] [PMC free article: 3948474] [doi: $10.1155 / 2014 / 869067]$

31. Ji X, Pushalkar S, Li Y, Glickman R, Fleisher K, Saxena D. Antibiotic effects on bacterial profile in osteonecrosis of the jaw. Oral Dis. 2012 Jan;18(1):85-95. [Medline: 21883710] [PMC free article: 3232327] [doi: $10.1111 / \mathrm{j} .1601-0825.2011 .01848 . x$ ]

32. Kaplan I, Anavi K, Anavi Y, Calderon S, Schwartz-Arad D, Teicher S, Hirshberg A. The clinical spectrum of Actinomycesassociated lesions of the oral mucosa and jawbones: correlations with histomorphometric analysis. Oral Surg Oral Med Oral Pathol Oral Radiol Endod. 2009 Nov;108(5):738-46. [Medline: 19748292] [doi: 10.1016/j.tripleo.2009.06.019]

\footnotetext{
To cite this article:

Silveira FM, Etges A, Correa MB, Vasconcelos AC. the Jaws in Rats

J Oral Maxillofac Res 2016;7(4):e3

URL: http://www.ejomr.org/JOMR/archives/2016/4/e3/v7n4e3.pdf

doi: $10.5037 /$ jomr.2016.7403
}

Microscopic Evaluation of the Effect of Oral Microbiota on the Development of Bisphosphonate-Related Osteonecrosis of

Copyright (C) Silveira FM, Etges A, Correa MB, Vasconcelos AC. Published in the JOURNAL OF ORAL \& MAXILLOFACIAL RESEARCH (http://www.ejomr.org), 28 December 2016.

This is an open-access article, first published in the JOURNAL OF ORAL \& MAXILLOFACIAL RESEARCH, distributed under the terms of the Creative Commons Attribution-Noncommercial-No Derivative Works 3.0 Unported License, which permits unrestricted non-commercial use, distribution, and reproduction in any medium, provided the original work and is properly cited. The copyright, license information and link to the original publication on (http://www.ejomr.org) must be included. 